\title{
Trigeminal Neuralgia as an Unusual Isolated Symptom of Pituitary Adenoma: Case Report and Review of the Literature
}

\author{
Oktay GURCAN ${ }^{1}$, Ahmet Gurhan GURCAY ${ }^{1}$, Atilla KAZANCl ${ }^{1}$, Ali Erdem YILDIRIM², Omer Faruk TURKOGLU', \\ Hatice Ferhan KOMURCU ${ }^{3}$, Ethem BESKONAKLI ${ }^{4}$
}

\begin{abstract}
${ }^{1}$ Ankara Ataturk Education and Research Hospital, Department of Neurosurgery, Ankara, Turkey
${ }^{2}$ Ankara Numune Education and Research Hospital, Department of Neurosurgery, Ankara, Turkey

${ }^{3}$ Ankara Ataturk Education and Research Hospital, Department of Neurology, Ankara, Turkey

${ }^{4}$ Ankara Medicana Hospital, Department of Neurosurgery, Ankara, Turkey
\end{abstract}

\section{ABSTRACT}

Pituitary adenomas account for approximately $10 \%$ of intracranial tumors and $5 \%$ are locally invasive. Cavernous sinus invasion by pituitary tumors presents mostly with cranial nerve palsies, especially involving the third, fourth and sixth cranial nerves, which is well documented in the literature. However, an isolated complaint of trigeminal neuralgia due to pituitary adenoma is an extremely rare entity with a limited number of reported cases. A 51-year-old female patient presented to our clinic with complaints of pain and numbness on the left side of face for six months, with each event lasting 5-10 seconds. No improvement was obtained with administration of carbamazepine therapy. Magnetic resonance imaging of the sellar region revealed a mass with the left cavernous sinus invasion. The patient underwent surgery via endoscopic transsphenoidal approach and after than radiosurgery with gammaknife. The patient's complaints resolved totally after gamma-knife radiosurgery. We report herein a case of pituitary adenoma with an isolated complaint of trigeminal neuralgia. Pituitary adenomas may be presented with cavernous sinus invasion and multiple cranial nerve palsies but isolated trigeminal neuralgia due to pituitary adenoma is an extremely rare entity.

KEYWORDS: Cavernous sinus, Pituitary adenoma, Trigeminal neuralgia

\section{INTRODUCTION}

Pituitary adenomas (PAs), which are benign tumors of the adenohypophysis, account for approximately $10 \%$ of intracranial tumors and $5 \%$ of adenomas, are locally invasive. PAs can be classified as hormone active adenomas and hormone inactive adenomas that can reach huge proportions without any sign or symptom (10).

Trigeminal Neuralgia (TN) is one of the most frequent cranial neuralgias. The incidence of TN is approximately 4 per 100 000 persons per year (9). TNs are paroxysmal attacks of pain lasting from a second to 2 minutes and affecting one or more divisions of the trigeminal nerve $(3,12)$. The pain of TN must have at least one of the following characteristics: as intense, sharp, stabbing, activated by trigger factors, without evident neurological deficit and not attributable to another headache cause $(3,12)$. Episodes of pain start unexpectedly and should last seconds to minutes. The non-painful stimulation of trigger points that located ipsilateral side of pain could initiated pain episodes. After the pain attacks, there is often a refractive period (14). The most common etiology for TN is disturbance of TN at the root entry zone by a vessel, generally the superior cerebellar artery. However, TN may be present in the absence of vascular contact (15).

The cavernous sinus (CS) is a form of large venous space containing the oculomotor nerve, trochlear nerve, ophthalmic and maxillary divisions of trigeminal nerve (located in the lateral wall) and also has internal carotid artery and abducent nerve (located in the central portion) (10). 

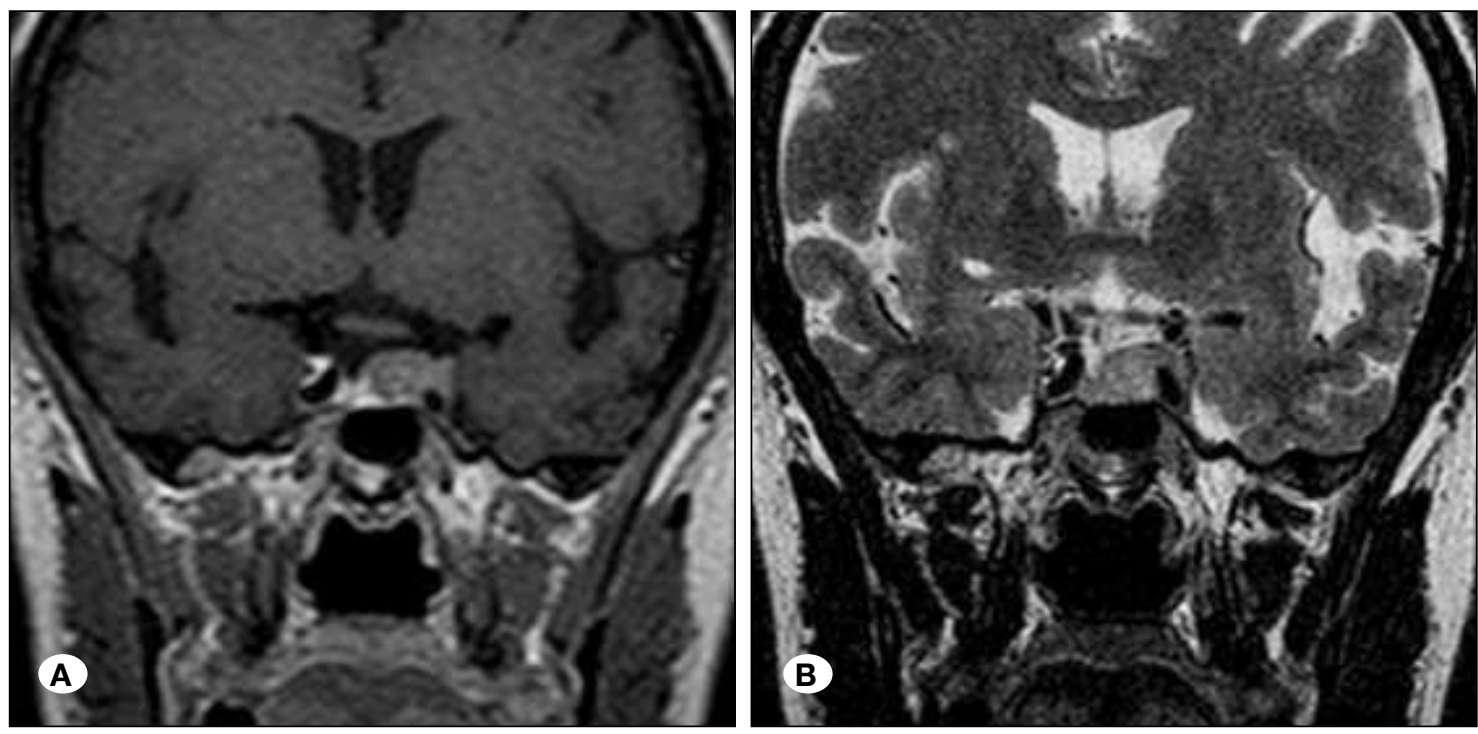

Figure 1:

A) Preoperative T1-weighted MRI scan with Gadolinium showing the pituitary mass lesion.

B) Preoperative T2-weighted MRI scan showing the pituitary mass lesion.

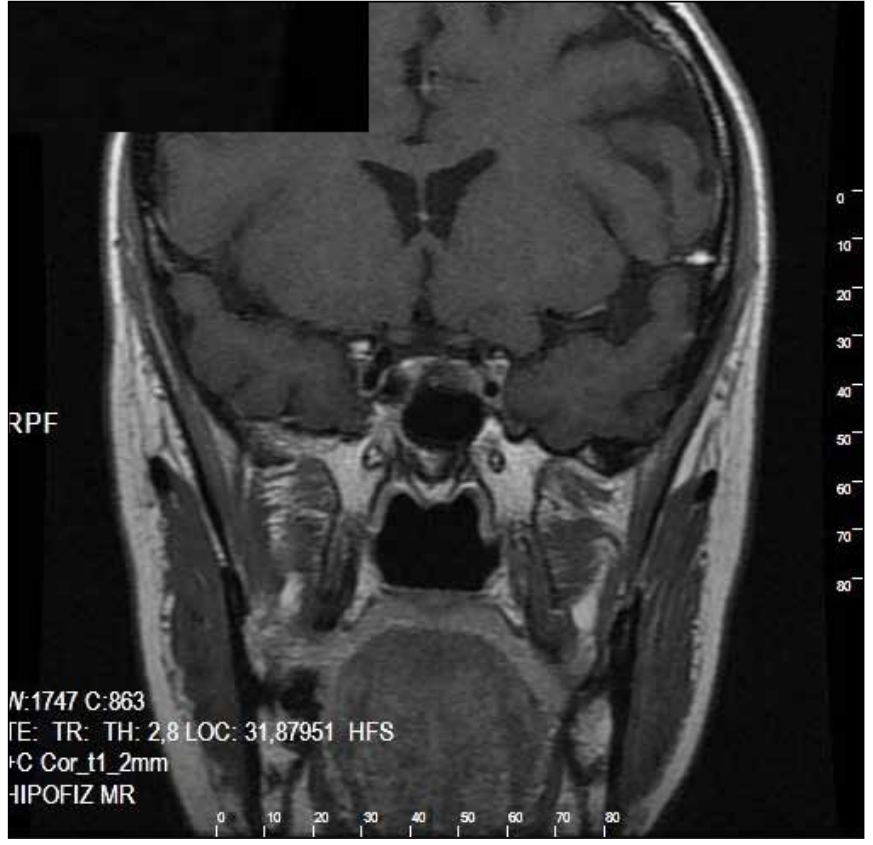

Figure 2: Postoperative T1-weighted MRI scan.

The preoperative diagnosis of CS invasion has an important role in the planning of surgical and adjuvant treatment strategies (22). In the event of CS invasion, cranial nerve findings are observed, especially pathologies of the third, fourth and sixth cranial nerves. However, isolated TN complaint due to invasion of CS by a PA is an extremely rare entity with a limited number of reported cases. Here, we reported a case of PA with an isolated complaint of $\mathrm{TN}$.

\section{- CASE REPORT}

A 51-year-old female patient admitted to our clinic with complaints of pain and numbness on the left side of face for six months. Her medical history revealed that the Neurology department had treated the patient as migraine attack with antimigraine drugs (such as zolmitriptan, frovatriptan) and then as ophthalmic, maxillar TN with Carbamezapine (200 mg of carbamazepine three times daily), but no improvement of symptoms was detected. On the neurological examination, numbness and lancinating pain on left side of her face without any other symptoms and signs were observed. The patient described the pain as sharp, the most intense pain that she had ever faced, and lasting for 5-10 seconds. The pain was radiating to gingiva, and was triggered by touching the left check while brushing her teeth. The patient had lost approximately $8 \mathrm{~kg}$ in weight because chewing also triggered the pain. Magnetic Resonance Imaging (MRI) of the sellar region revealed mass with invasion to the left CS (Figure $1 \mathrm{~A}, \mathrm{~B})$. According to the Wilson's classification of large and invasive pituitary tumor we classified this mass lesion as "E" as CS invasion (24). According to Knosp's classification, the mass lesion was classified as " 3 " (13). The endocrinological evaluation revealed no abnormality. A clinical diagnosis of PA was made, and the patient underwent surgery via endoscopic transsphenoidal approach. Postoperatively, the patient's complaints partially resolved (approximately 80\%), and she was discharged uneventfully. Immuno-histological studies revealed non-functioning PA. The patient underwent gammaknife radiosurgery for the residual mass and her complaint's resolved totally after radiosurgery (Figure 2). After 36 months of follow-up period medical treatment the patient had no complaints of facial pain or numbness.

\section{DISCUSSION}

PAs typically cause compression of neighboring structures and enlargement of sellae. On the other hand, some PAs may demonstrate aggressive behavior so as to infiltrate the sphenoid sinus, diaphragma sellae and CS (22).

In the preoperative period, investigations begin with neurological and endocrinological examinations. For radiological test observation, MRI is the gold standard of diagnostic imaging 
for demonstrating the relationship of the tumor with the optic nerve, CS and third ventricle (22).

PAs that invade CS may cause headache directly, and there are reports in the literature about headache that respond to pituitary medical or surgical therapy $(5-8,11,16,18-21,23)$. On the other hand facial pain such as TN and numbness of the face on the same side of CS invasion, are extremely rare in the literature. TN is a form of headache that could have been misdiagnosed as other causes of facial pains such as toothache, atypical facial pains, migraine attacks, and cluster headaches. The differential diagnosis could be made by excluding the other facial pains. Migraine is a form of episodic headache with nausea and photophobia. There could be aura and transient neurological deficit (somatosensory symptoms involving the hand and face) atypical facial pain could be defined as "persistent facial pain" which could not be attributed to any other form of facial pain $(10,12)$. In this case the patient had the characteristic pain history such as sharp, stabbing pain episodes lasting for seconds. After the pain attacks she described some refractory period. Non painful stimulation of the trigger points had caused the pain attacks as an example chewing and brushing teeth $(3,12,14)$. In the history of the patient there were no predisposing conditions such as bright light, stress, and diet changes. Also the patient did not describe any auras.

John Locke identified the major clinical features of TN in 1677 (1). According to the International Classification of Headache Disorders, the classical form of TN is caused by vascular compression of the trigeminal nerve root in the dorsal root entry zone, while the symptomatic form has other causes such as tumors and multiple sclerosis (9). However, PAs, as a cause of TN, as in our case, are extremely rare cause. Micro vascular decompression, internal neurolysis, or radiofrequency, sensory rhizotomy, balloon rhizotomy, glycerol injections, and radiosurgery have been reported as treatment modalities (15). Radiosurgery for TN is preferred for idiopathic cases and also for cases resistant to medical therapy. In our case it was not an idiopathic case so we treated the residual PA with gammaknife radiosurgery.

Invasion of CS by a PA increases morbidity and mortality because complete resection of the tumor is usually not possible. Adjuvant therapies, such as radiosurgery, are often needed when partial resection is performed (22). In our case we performed endoscopic trans-sphenoidal approach to the pituitary mass and preferred Gamma knife radiosurgery for the residual lesion in the CS.

When the CS is invaded by a PA, clinical findings are often associated with the third, fourth, fifth, and sixth cranial nerves. However, TN as an isolated symptom of PA invasion of the CS is extremely rare. A review of the English literature revealed a few cases related with PA and TN. Freidman et al. reported two cases of facial pain associated with PA. In that report one of the patients was presented with Raeder's syndrome and developed partial third nerve palsy. The second patient complained of tic douloureux with no localizing neurological deficit (5). Leone et al. reported a 49-year-old man with cluster-tic syndrome that resolved after removal of PA (17).
Ferrari et al. reported bromocriptine-induced ophthalmic TN as an isolated symptom of non invasive PA. In that case the patient suffered ophthalmic TN as an isolated symptom of a non-invasive PA. The patient's TN attacks were provoked by bromocriptine and provocation was prevented usage of domperidone. TN attacks were resolved with pituitary surgery (4). In a study reported by Bullitt et al. in 2000 patients with TN, only one case had associated PA (2). Gazioglu et al. reported a 24-year-old man who was suffering from ophthalmic and maxillary $\mathrm{TN}$ as an isolated symptom caused by invasion of the left CS by pituitary macroadenoma and also reported that TN symptoms resolved after adenomectomy, as experienced in our case (7).

While PA may present with CS invasion and multiple cranial nerve palsies, isolated TN due to $\mathrm{PA}$ is an extremely rare entity. Here, we reported a case of PA with an isolated complaint of TN. The patient's complaints totally resolved with adeno-mectomy and gamma-knife radiosurgery, and after 36 months of follow-up, the patient had no complaints of facial pain or numbness. TN must be evaluated carefully, and possible etiological causes must be kept in mind to facilitate appropriate management of the pain.

\section{- REFERENCES}

1. Ameli NO: Avicenna and trigeminal neuralgia. J Neurol Sci 2(2): 105-107, 1965

2. Bullitt $E$, Tew $J$ M, Boyd J: Intracranial tumors in patients with facial pain. J Neurosurg 64:865-871, 1986

3. Cruccu G, Gronseth G, Alksne J, Argoff C, Brainin M, Burchiel K, Nurmikko T, Zakrzewska JM: AAN-EFNS guidelines on trigeminal neuralgia management. American Academy of Neurology Society; European Federation of Neurological Society. Eur $\mathrm{J}$ Neurol 15:1013-1028, 2008

4. Ferrari MD, Haan J, Van Seters AP: Bromocriptine-induced trigeminal neuralgia attacks in a patient with pituitary tumor. Neurology 38(9): 1482-1484, 1988

5. Friedman $\mathrm{AH}$, Wilkins $\mathrm{RH}$, Kenan PD, Olanow CW, Dubois PJ: Pituitary adenoma presenting as facial pain: Report of two cases and review of the literature. Neurosurgery 10: 742-745, 1982

6. Gabrielli M, Gasbarrini A, Fiore G, Santarelli L, Padalino C, De Martini D, Giacovazzo M, Pola P: Resolution of migraine with aura after successful treatment of a pituitary microadenoma. Cephalalgia 22: 149-150, 2002

7. Gazioglu N, Tanriover N, Tuzgen S: Pituitary tumour presen-ting with trigeminal neuralgia as an isolated symptom. $\mathrm{Br} \mathrm{J}$ Neurosurg 14: 579, 2000

8. Gelabert Gonzalez M, Bollar Zabala A, Garcia Allut A: Trigeminal neuralgia as the first manifestation of craniopharyngioma. An Med Interna 7: 545, 1990

9. Grasso G, Passalacqua M, Giambartıno F, Cacciola F, Caruso G, Tomasello F: Typical trigeminal neuralgia by an atypical compression: Case report and review of the literature. Turk Neurosurg 24(1):82-85, 2014

10. Greenberg MS: Handbook of neurosurgery. In: Pituitary Adenoma, 6th ed. New York: Thieme Press, 2006: 438-456

11. Greve E, Mai J: Cluster headache-like headaches: A symptomatic feature? A report of three patients with intracranial pathologic findings. Cephalalgia 8:79-82, 1988 
12. Headache Classification Subcommittee of the International Headache Society: The international classification of headache disorders: 2nd ed. Cephalalgia 24 Suppl 1: 9-16, 2004

13. Knosp E, Steiner E, Kitz K, Matula C: Pituitary adenomas with invasion of the cavernous space. Magnetic resonance imaging classification compared with surgical findings. Neurosurgery 33(4):610-618, 1993

14. Kumar S, Rastogi S, Kumar S, Mahendra P, Bansal M, Chandra L: Pain in trigeminal neuralgia: Neurophysiology and measurement: A comprehensive review. J Med Life 6(4): 383-388, 2013

15. Lee A, McCartney S, Burbidge C, Raslan AM, Burchiel KJ: Trigeminal neuralgia occurs and recurs in the absence of neurovascular compression. J Neurosurg 120:1048-1054, 2014

16. Lee AH: Pituitary adenoma causing classical migraine. $\mathrm{Br} \mathrm{J}$ Neurosurg 4: 347-348, 1990

17. Leone M, Curone M, Mea E, Bussone G: Cluster-tic syndrome resolved by removal of pituitary adenoma: the first case. Cephalalgia 24: 1088-1089, 2004

18. Miles JL: The association of pituitary tumors and headache. Curr Neurol Neurosci Rep 11: 164-170, 2011
19. Millan-Guerrero RO, Isais-Cardenas MA: Headache associated with pituitary adenomas. Headache 39: 522-523, 1999

20. Porta-Etessam J, Ramos-Carrasco A, Berbel-Garcia A, MartínezSalio A, Benito-León J: Clusterlike headache as first manifestation of a prolactinoma. Headache 41:723-725, 2001

21. Tfelt-Hansen $P$, Paulson $O B$, Krabbe AA: Invasive adenoma of the pituitary gland and chronic migrainous neuralgia. $A$ rare coincidence or a causal relationship? Cephalalgia 2:25-28, 1982

22. Vieira JO Jr, Cukiert A, Liberman B: Magnetic resonance imaging of cavernous sinus invasion by pituitary adenoma. Diagnostic criteria and surgical findings. Arq Neuropsiquiatr 62(2-B):437-443, 2004

23. Williams G, Ball JA, Lawson RA, Joplin GF, Bloom SR, Maskill MR: Analgesic effect of somatostatin analogue (octreotide) in headache associated with pituitary tumours. Br Med J (Clin Res Ed) 295:247-248, 1987

24. Wilson CB, Tyrell JB, Fitzgerald PA: Neurosurgical management of large and invasive pituitary tumors. In: Thindall GT, Collins WF (eds). Clinical Management of Pituitary Disorders. New York: Raven Pres, 1979:335-342 